\title{
EXPERIMENTAL STUDY ON VIBRATION AND NOISE OF MINIBUS REAR DRIVING AXLE
}

\author{
Dequan $\mathrm{Jin}^{1,2, \mathrm{a}}$,Qidong Wang ${ }^{1, \mathrm{~b}}$, Huibin $\mathrm{Li}^{3, \mathrm{C}^{*}}$, Mengyin $\mathrm{Gu}^{3, \mathrm{~d}}$ \\ ${ }^{1}$ School ofMechanical and Automotive Engineering, HEFEI UNIVERSITY OF TECHNOLOGY, \\ Hefei, Anhui, China, 230009 \\ ${ }^{2}$ Foton Daimler Automotive, Beijing,China,101400 \\ ${ }^{3}$ School of Mechanical and Vehicular Engineering, Beijing Institute of Technology, Beijing, \\ China,100081 \\ ajindequan@bfda.cn, ’qdwang@aust.edu.cn, huibinli@163.com, 'gumengyinyin@163.com
}

Keywords: Vibration; Noise; Driving axle; Minibus

\begin{abstract}
Test of interior and external noise and vibration signals of Minibus were conducted in accelerating and constantvelocity driving conditions. By using time domain, frequency domain and 3D spectral arraymethods, the exterior noise, interior noise, the vibration acceleration of driver's seat and driving axle,the NVH characteristics of the Minibus were analyzed. On the one hand, we find that theinterior noise is larger than exterior noise under accelerating state, due to the cabin poorly sealing.On the other hand, because of the poor isolation rate of the suspension and the huge noise and vibration of driving axle and power train, the interior noise is very great and affecting the driver's comfort. The experimental results shows that the main frequency components of interior noise consist of two parts, one is the low frequency which origins from vibration exciting of the power train, and the other is the middle and high frequencies which origin from vibration exciting of the driving axle and transmission system. Theseexperimental results will give help to further study of the NVH characteristic of the Minibus.
\end{abstract}

\section{Introduction}

The NVH problem of the automotive is one of most important factors affecting the ridecomfort and customer's acceptance. The NVH engineer and researchers have done a lot of job tostudy the interior noise, external noise and vibration, and have achieved great successes for thevehicle with the traditional combustion engine and pure electric motor[1-3]. Experimentalmethods are the basic way to analyze the interior, exterior acoustic characteristic and vibration ofthe automobile[4-10]. HANG Chunxiang(2009) tested the noise spectrum of pure EV motorsystem. HE Luchang(2010) tested the sound and vibration characteristic of a new electrical vehiclein the four-wheel tumbler test bench of semi-freedom noise elimination chamber, and analyzed thedistribution of internal noise and main frequency ingredients at different speeds.The authors (2010, 2011, 2012) havecarried out a series of bench tests and road tests on the driving axle of minibus, identified the sound sources andvibration sources of the driving axle and revealed the relationship among the discomfort,vibration and noise of the driving axle.

This paper introduces a NVH test on Minibus and analyzes the interior sound field characteristic, externalaccelerating noise and the vibration signals at driver's seat, the bottom of driver's seat anddriving axle.

\section{Measurement of noise and vibration under accelerating state}

The accelerating noise test was carried out on the National standard noise test road, by usingno-load test method. Fig.1 is the layout of road accelerating NVH test. Fig.2 is the picture of Foton minibus. 


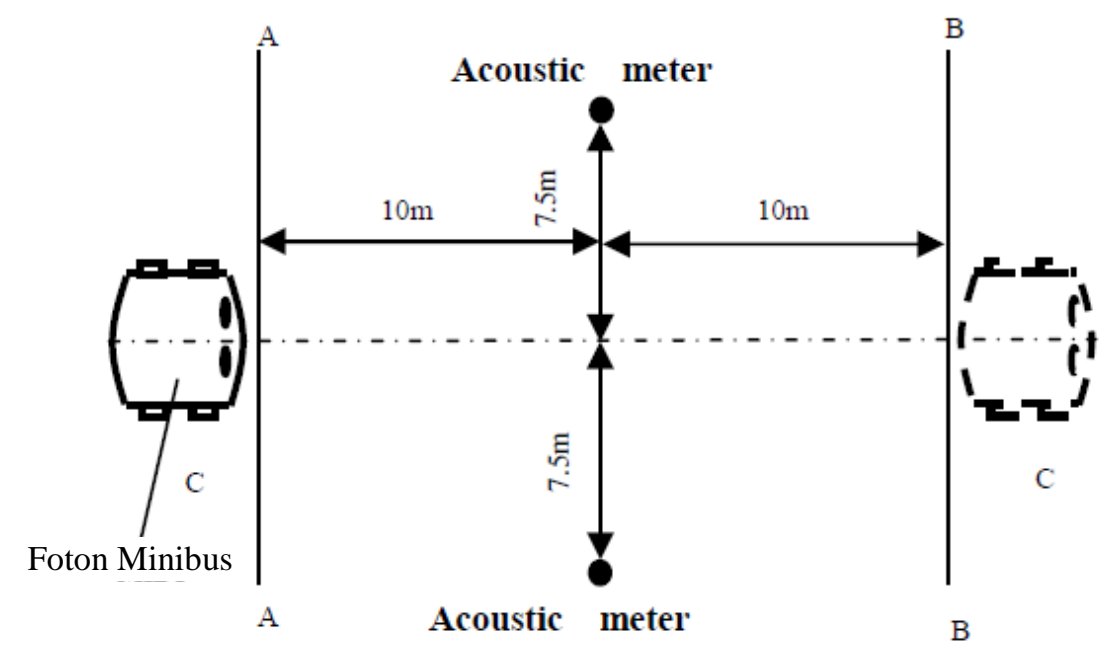

Fig.1 Layout of road accelerating noise testing

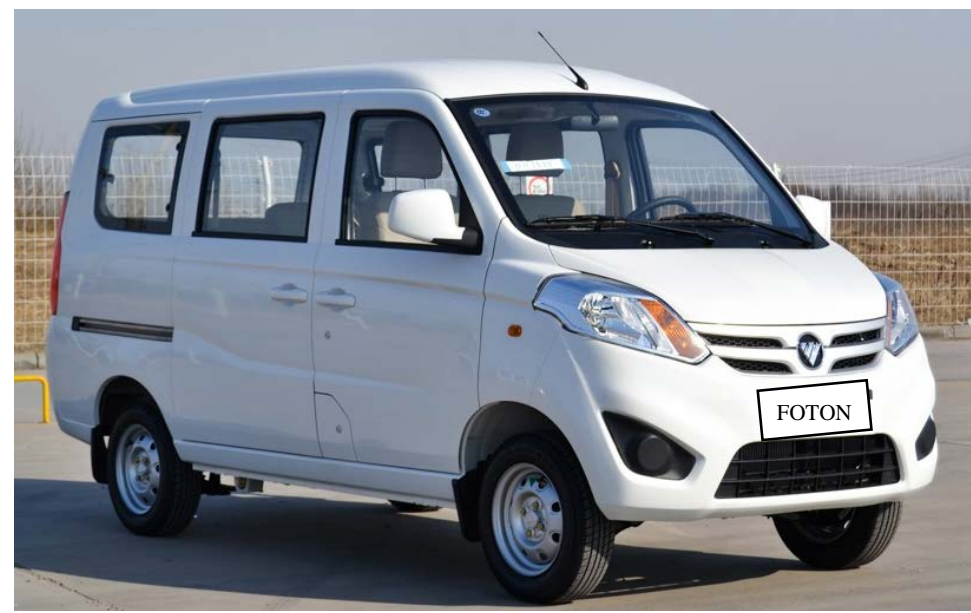

Fig.2 The picture of FOTON Minibus

During the test, when the minibus driven to the line C-C, throttle fully opened and the minibuswasaccelerated and passed through the $20 \mathrm{~m}$ long test track. The initial velocities for accelerating were $40,50,60 \mathrm{~km} / \mathrm{h}$, respectively. As the main frequencies of vibration and noise were less than $2000 \mathrm{~Hz}$,so the sampling rate was set as $5120 \mathrm{~Hz}$. The data acquisition system was DASP 306.The noise signal atboth diver's ear side in cab and road side were measured synchronously.

\subsection{Measurement ofinterior noise and main reducer's noise}

Fig. 3 shows the interior noise and the main reducer's noise with different gear stalls under accelerating state. From this figure, we can find out that the interior noise level during accelerating is obvious,as high as 77.3dBA at driver's ear. The firstnoise source for causing interior noise larger may be from power train's noise and vibration, and the second noise source may be from driving axle. 


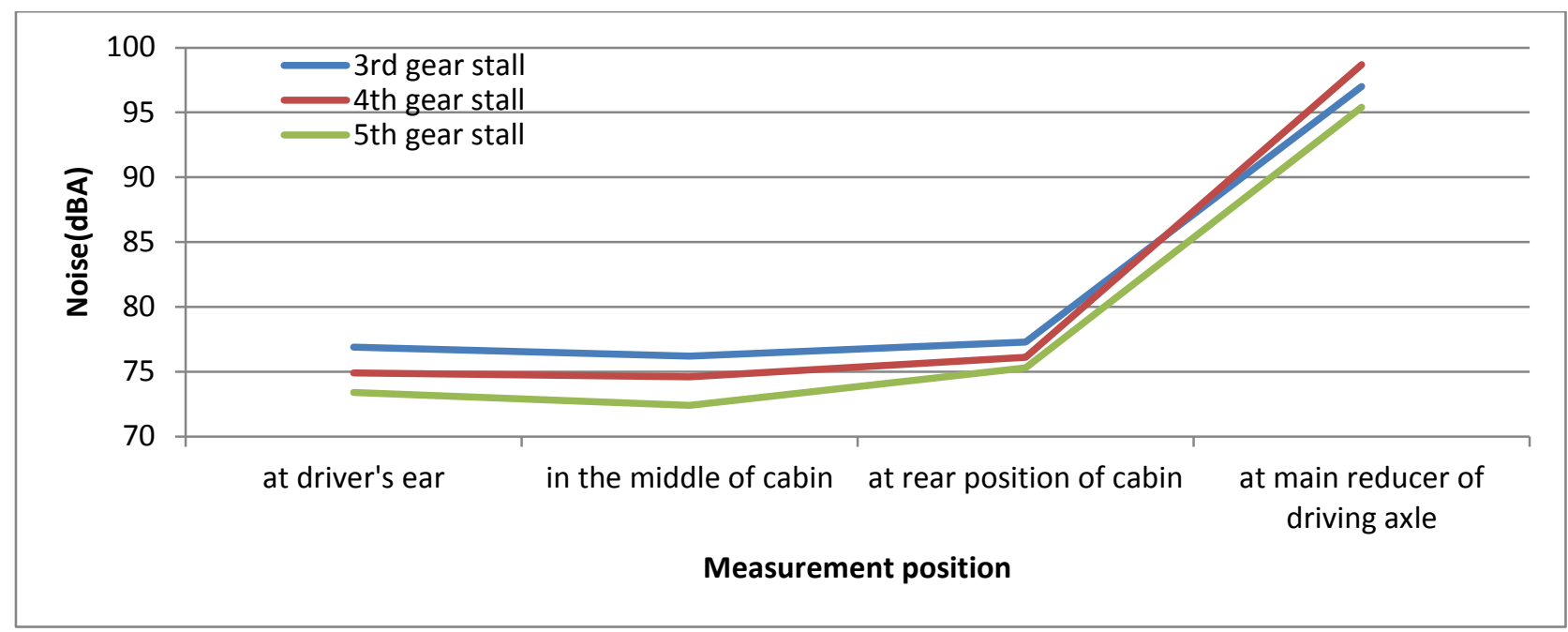

Fig.3 Interior noise and the main reducer’s noise under accelerating state

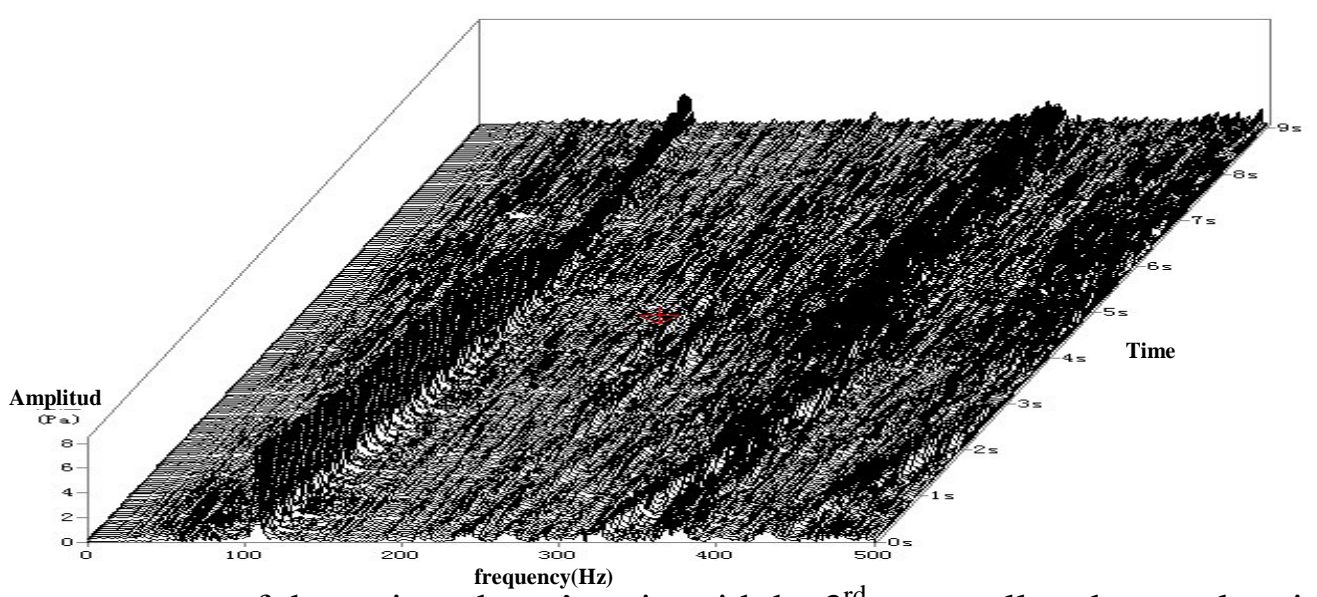

Fig.4 Spectrum array of the main reducer's noisewiththe $3^{\text {rd }}$ gear stall under accelerating state

$(0-500 \mathrm{~Hz})$

\subsection{Measurement of external noise}

Fig. 5 shows the changes of external noise on both sides of the road under different gearstalls. From this figure, we can find out that the noise level decreases with gear stalls,and the noise level on both sides of the road are slightly different. According to Fig.6(a) andFig.6(b), we could discover that the external noise on both sides of the road is narrow band noise,concentrating at $106 \mathrm{~Hz}$ and its harmonic components, mainly from power train noise and partly from transmission system noise.

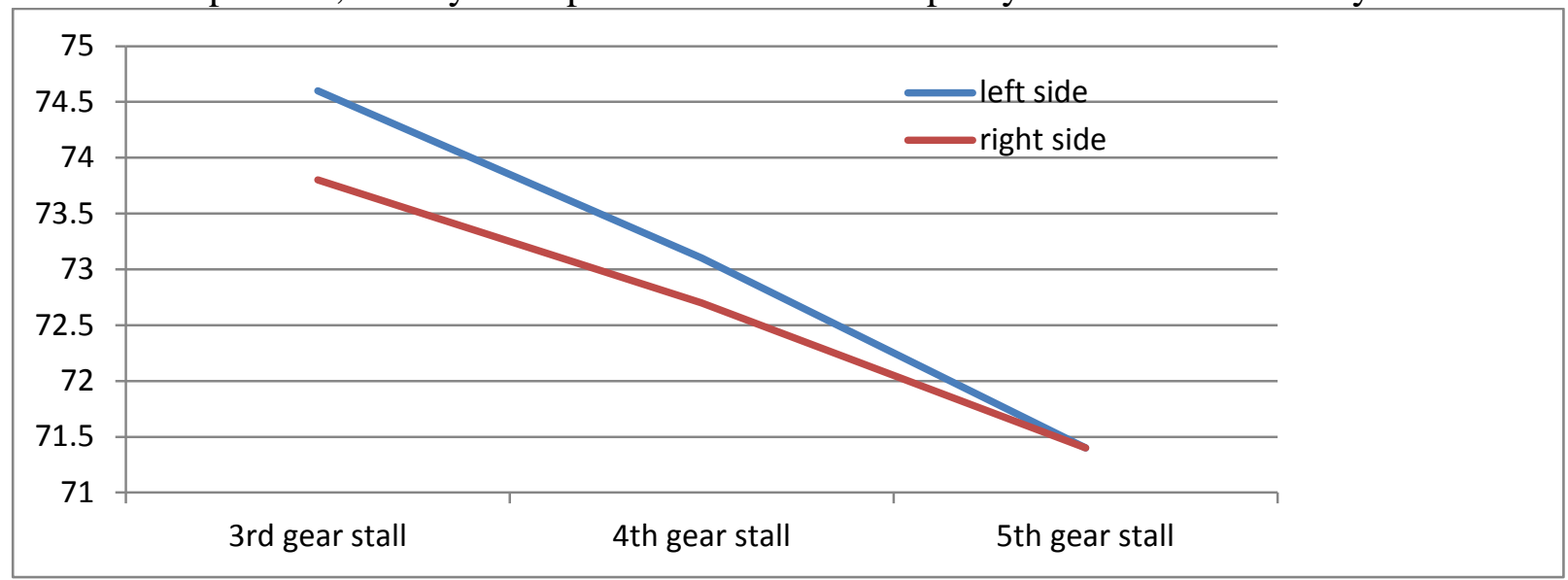

Fig.5 External noise on both sides of the road under acceleration state 

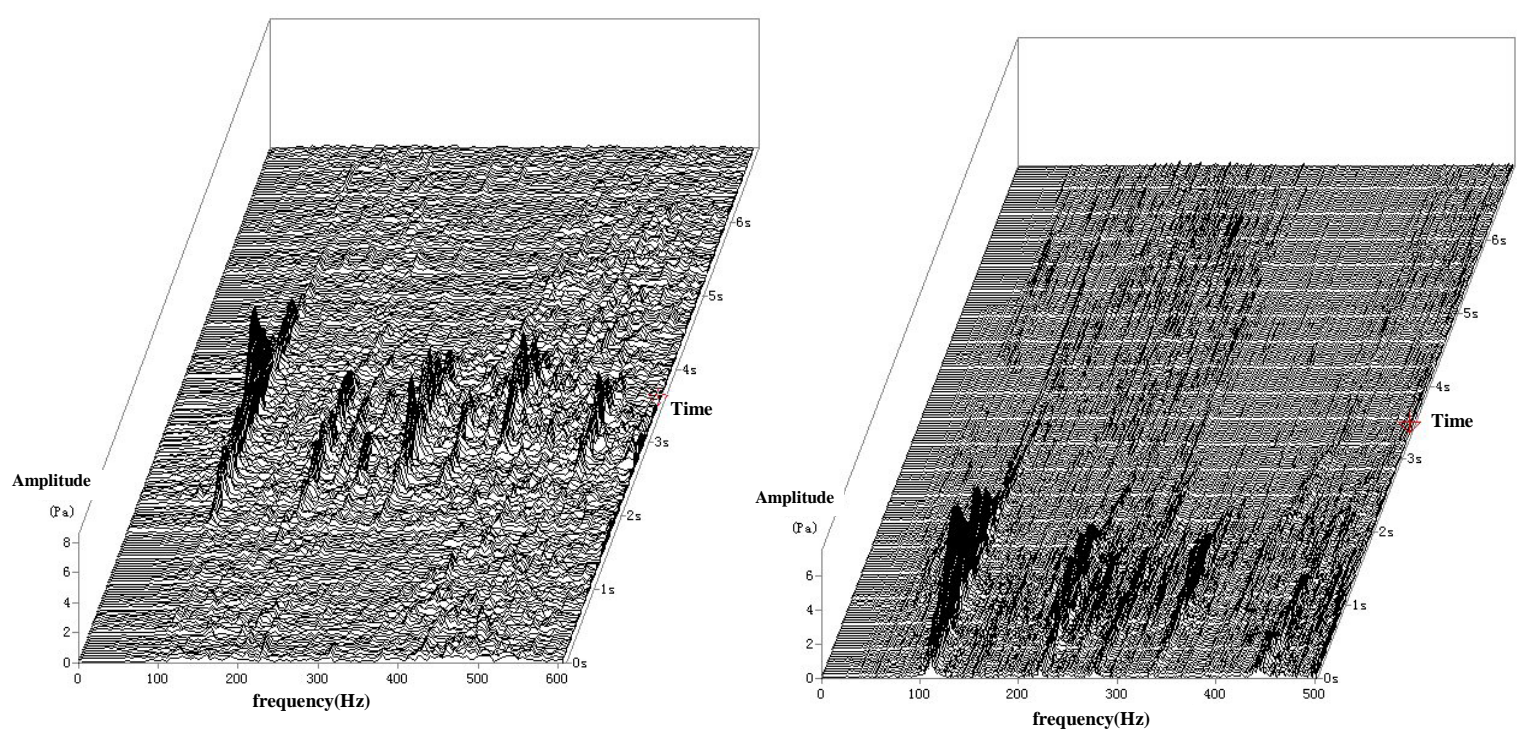

(a) left side (b) right side

Fig.6 Spectrum of external noise under acceleration from $50 \mathrm{~km} / \mathrm{h}$ with $3^{\text {rd }}$ gear stall

\subsection{Test on vibration under accelerating state}

Fig.7 shows vibration measurement results at main reducer, at seat base and at seat under different gear stalls. From this figure, we can find out that the vibration level at main reducer is very high,but the vibration isolation rate of seatis good.

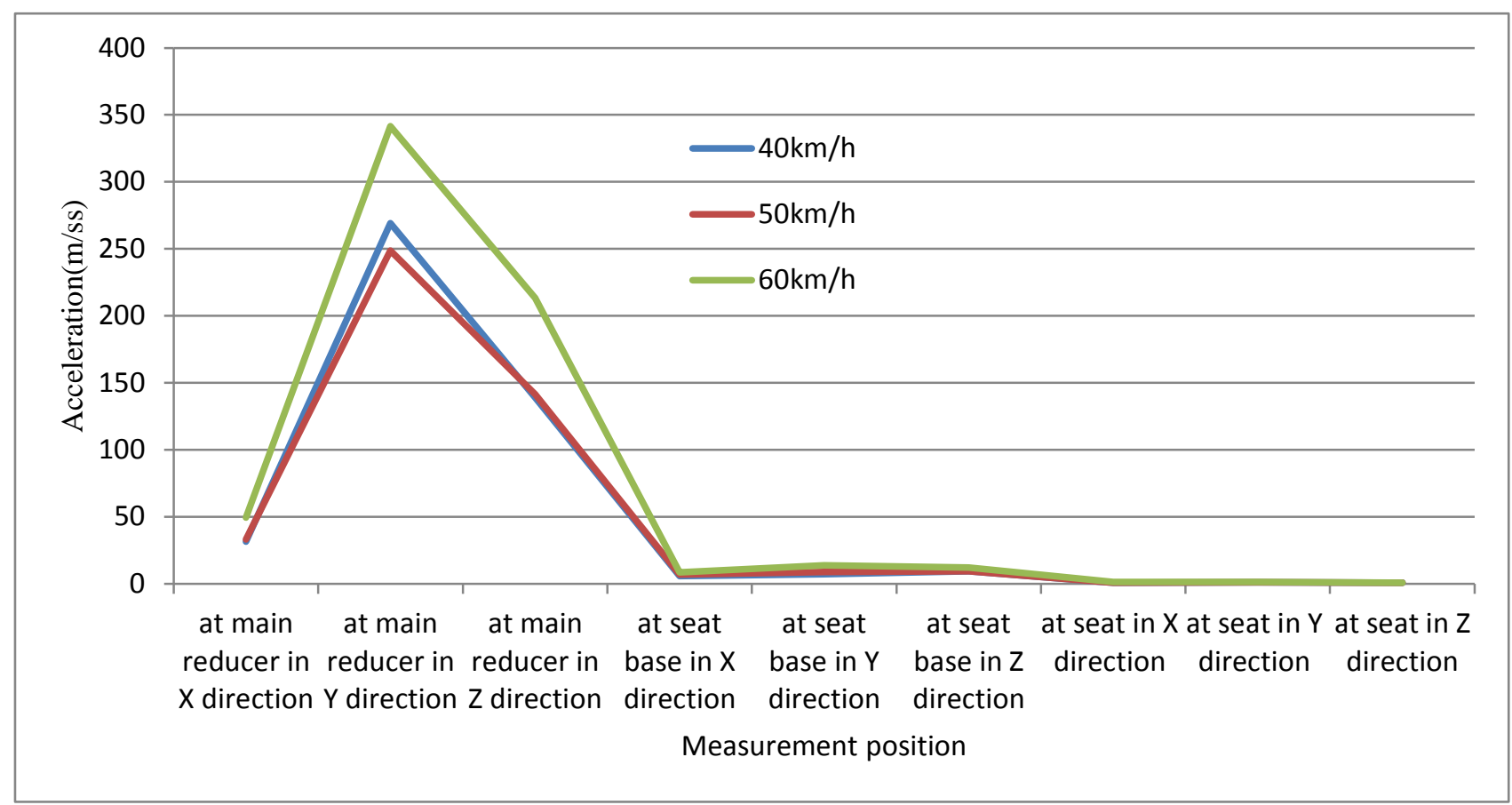

Fig.7 Vibration measurement under accelerating state from $50 \mathrm{~km} / \mathrm{h}$

\section{Noise and vibration testing under constant driving velocity}

In order to obtain the actual noise level and vibration level under constant velocities, the drivingvelocities of 40,50 and $60 \mathrm{~km} / \mathrm{h}$ were taken respectively.

\subsection{Noise tests}

Under constant driving velocities of 40,50 and $60 \mathrm{~km} / \mathrm{h}$, interior noise changes with thevelocities and gear stalls and reaches as high as $74.7 \mathrm{dBA}$ at the rear part of the cabin, shown in Fig.8. At the speed of $40 \mathrm{~km} / \mathrm{h}$, the coherent coefficient between noise at driver's ear and noise at main reducer reaches the maximal value of 0.88 at the frequency of $1124 \mathrm{~Hz}$, and at the speed of 
$50 \mathrm{~km} / \mathrm{h}$, the coherent coefficient between noise at driver's ear and noise at main reducer reaches 0.57 at the frequency of $814 \mathrm{~Hz}$. According to Fig.9, the coherent coefficient between noise at driver's ear and noise at main reducer reaches 0.73 at the frequency of $819 \mathrm{~Hz}$. So to a large extent, the noise at driver's ear comes from the main reducer's noise.

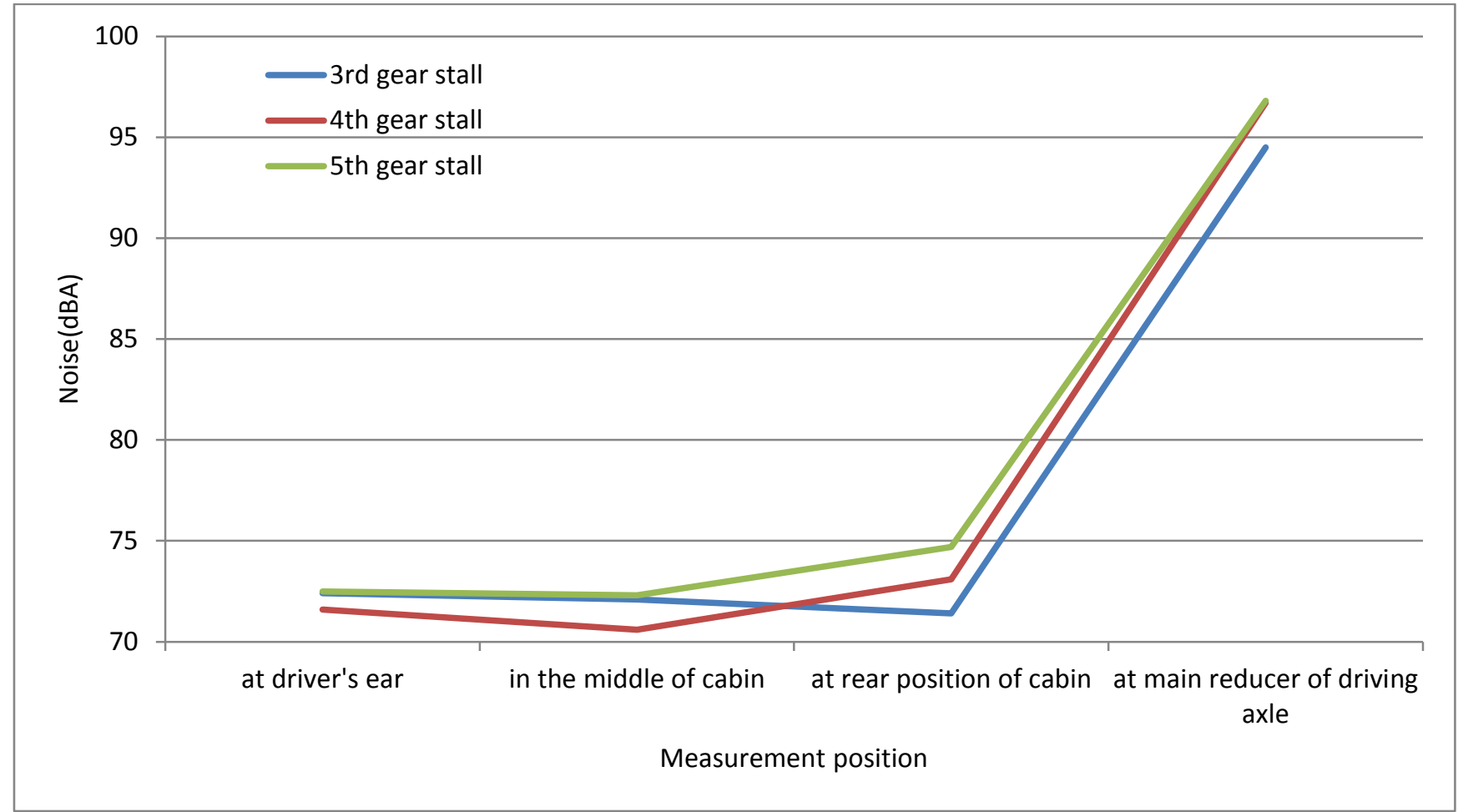

Fig.8 Interior noise under constant driving velocity
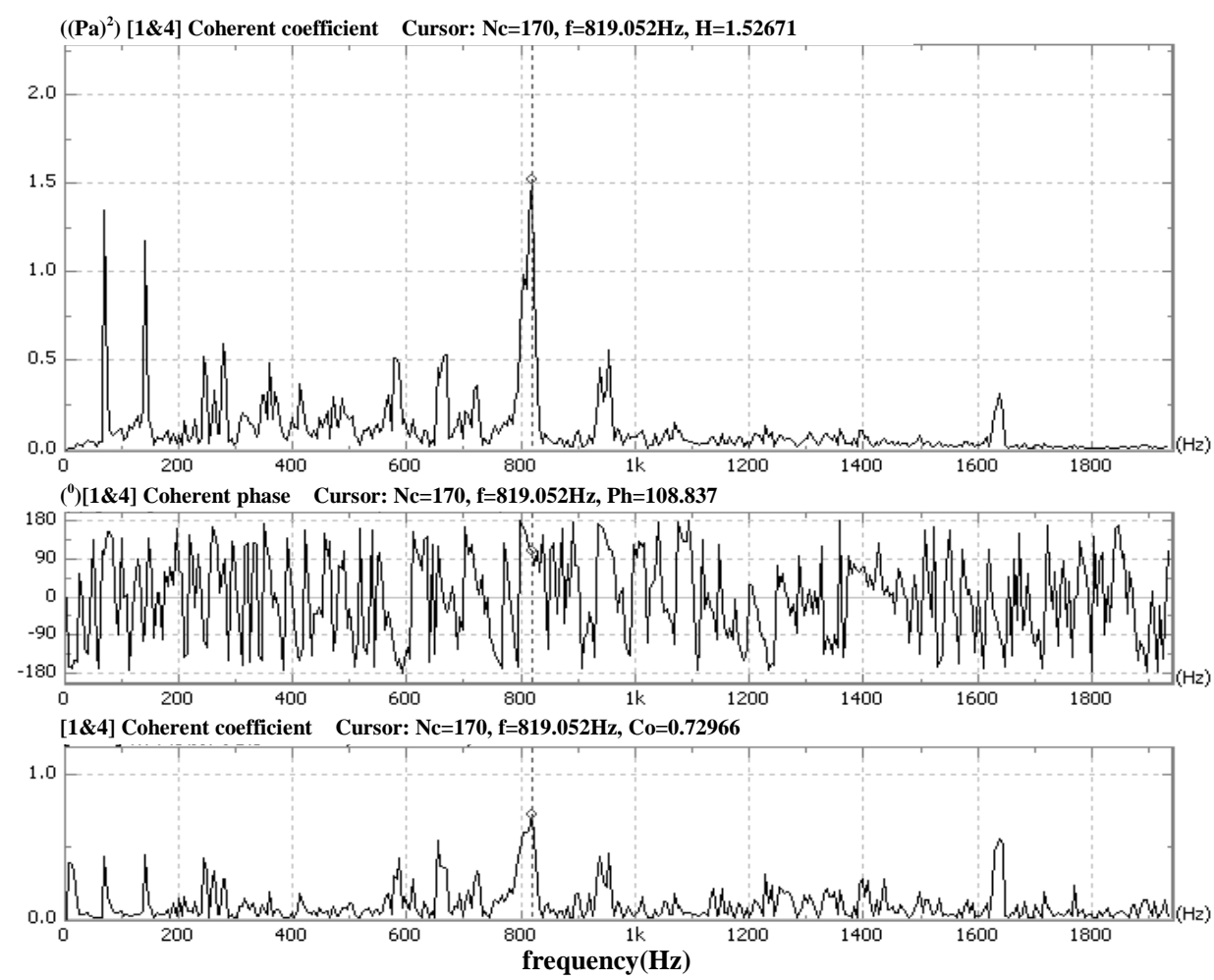

Fig.9Coherent analysis between noise at driver's ear and noise at main reducer under speed of $60 \mathrm{~km} / \mathrm{h}$ 


\subsection{Vibration tests}

Under constant driving velocities of 40,50 and $60 \mathrm{~km} /$ hwith three gear stalls, the vibration accelerationat three positions on minibus are shown inFig.10, Fig.11 and Fig.12, and Fig.13 is spectrum of vibration at main reducer with $3^{\text {rd }}$ gear stall. The vibration acceleration at main reducerroughly increases with the velocities at three gear stalls. From the three figures, we also find that the isolation rate of the driver's seat is good. So the vibration of main reducer must be improved.

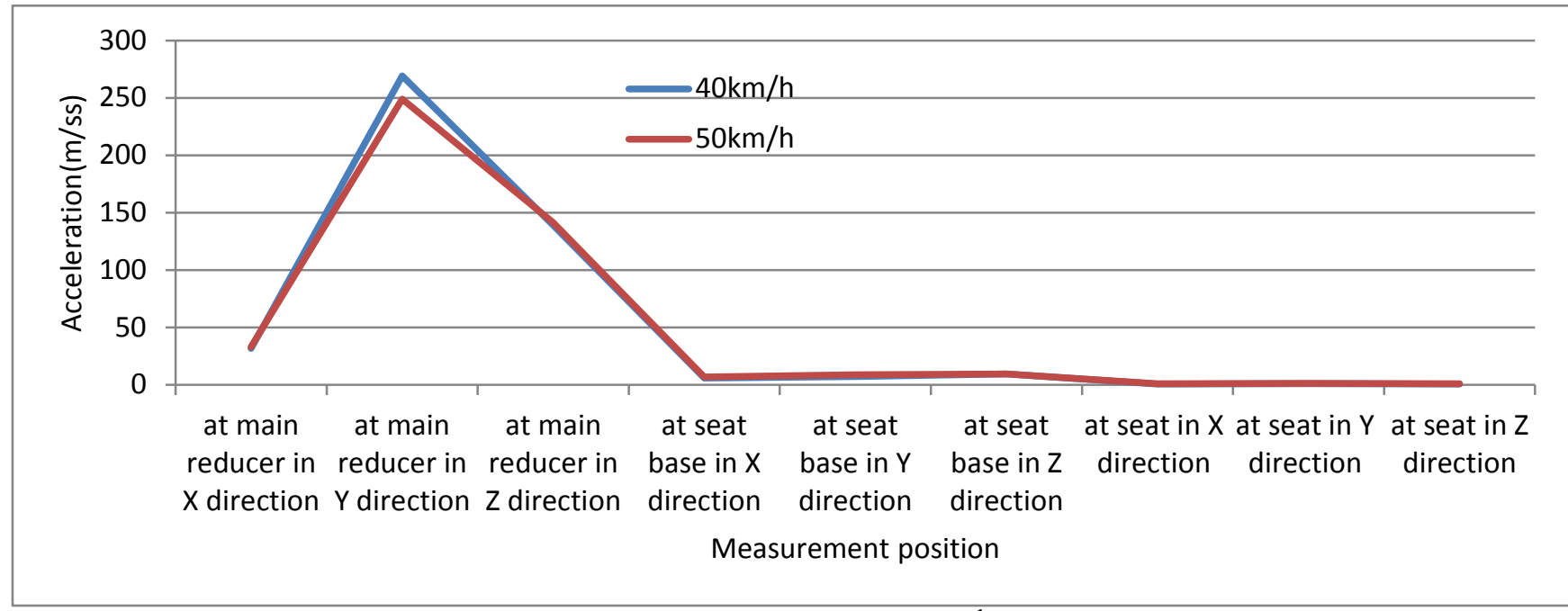

Fig.10 Vibration measurement with $3^{\text {rd }}$ gear stall

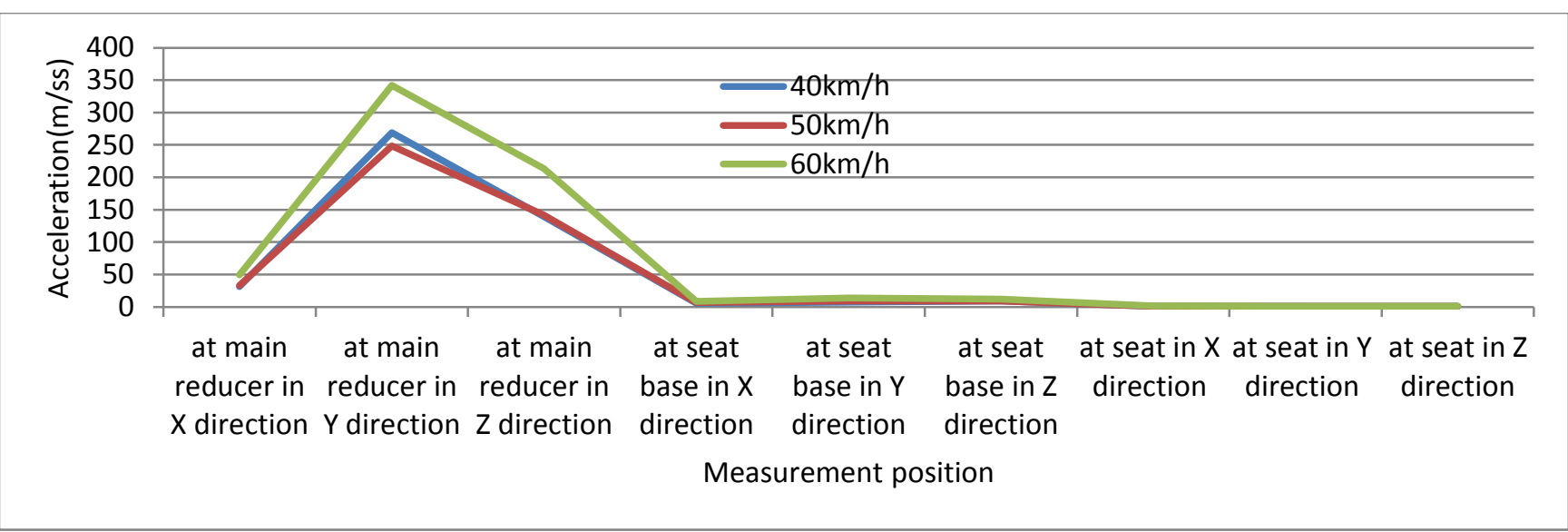

Fig.11 Vibration measurement with 4th gear stall

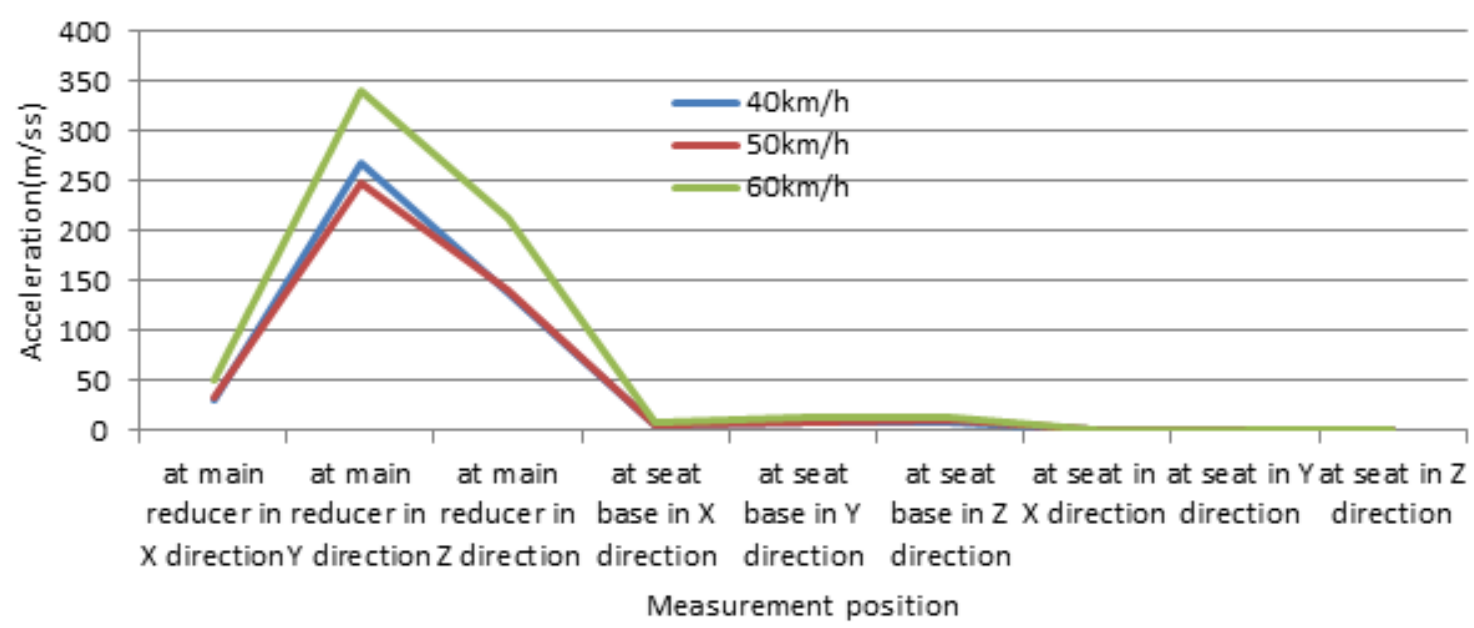

Fig.12 Vibration measurement with 5th gear stall 


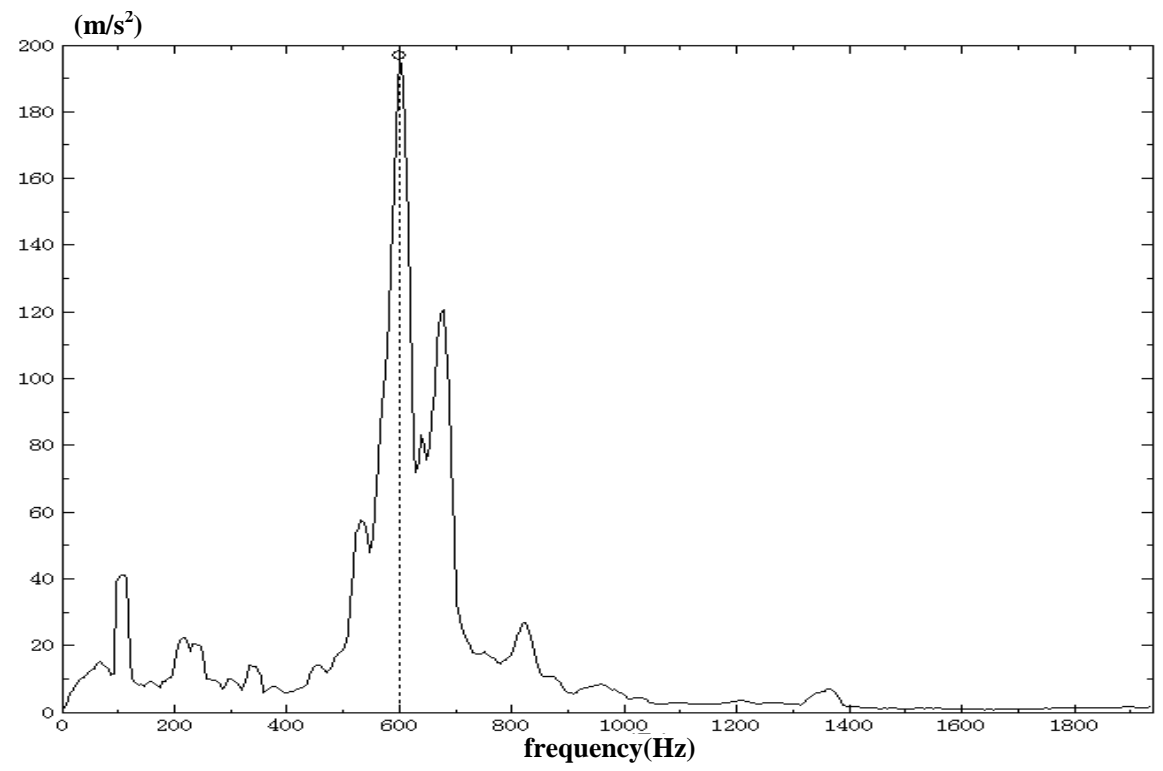

Fig.13 Spectrum of vibration at main reducer with $3^{\text {rd }}$ gear stall

\section{Conclusion}

This paper introduces a NVH test on minibus, and analyzes the interior sound field characteristic, externalaccelerating noise and the main vibration signals at different positions of minibus. The conclusions are reached as following:

(1) The main reasons for causing interior noise largely is from power train and main reducer of driving axle. If the cabin issealed well, then this kind of noise will be reduced.

(2) The exterior noise on both sides of the road is narrow band noise, concentrating at $106 \mathrm{~Hz}$ and its harmonic components, mainly from power train noise and partly from transmission system noise.

(3)Under constant driving velocities of 40,50 and $60 \mathrm{~km} / \mathrm{h}$ with threedifferent gear stalls, the vibration acceleration at main reducerroughly increases with the velocities at three gear stalls. The coherent coefficient between noise at driver's ear and noise at main reducer reaches high at the main noise frequencies. So to a large extent, the noise at driver's ear comes from the main reducer's noise and the vibration of main reducer must be improved.

(4) These results will give help to further study of the NVH characteristic of the minibus.

\section{Acknowledgements}

The authors express their gratitude to the Natural Science Foundation of China (50875022) for the financial support of the study.

\section{References}

[1] LI Huibin. Reports on optimization analysis of the commercial vehicle driving system for Chongqing Changan Automobile Company. Beijing Institute of Technology, 2012. [In Chinese]

[2] Li Huibin, Zhang Chenxia, Li Quanxi, Jin Ting, Wang Kefeng. Experimental Study on NVH Performance of Midi Pure Electric Vehicle.Source:2012 International Conference on Mechanical Engineering and Materials, ICMEM 2012, PART 3, pp1852-1857, 2012.

[3] Jin Ting. Structure dynamical analysis of a commercial automobile driving axle. Dissertation for the degree of Master of Beijing Institute of Technology, 2010. [In Chinese]

[4] Yi Chuijie, Zhang Jian, Song Leiming. Analysis and Investigation of Noise Caused by Automotive Rear Axle. Automotive Engineering, 1994,16(5):289-295. [In Chinese] 
[5] ZHANG Chunxiang, HAO Renpu, WANG Zai-zhou. Research of Noise SpectrumCharacteristics of Traction Motor System for Electric Vehicle. Micromotors. 2009, 42:73-74.[InChinese]

[6] HE Luchang, ZUO Shuguang, HE Rong, etc. Analysis of Noise and Vibration for a New PureElectrical Vehicle, ICACTE2010, pp435- 438.

[7] ShuguangZuo, JiaoYan. Experimental analysis for the interior noise characteristics of the fuelcell car. 2006 IEEE International Conference on Vehicular Electronics and Safety, ICVES, pp241-245, 2006.

[8] HUANG Fengyun,GUO Jingyan,QI Fan,LI Changda, HUANG Fengyun. Fault Detection of Main Reducer Gear Engagement on Automobile Rear Axle. Journal of Wuhan University of Technology, 2012, 34(3): 301-305. [In Chinese]

[9] Harrison.M.Vehicle Refinement-Controlling Noise and Vibration in Road Vehicles. Elsevier Butterworth-Heinemann Linacre House,Jordan Hill, 2004.

[10]PENG Jian, ZHAN Gang, He Hua. Automotive Noise and Vibration-Principle and Application. Beijing Institute of Technology Press,2006. [In Chinese] 